\title{
Activation of Metabotropic Glutamate Receptors Differentially Affects Two Classes of Hippocampal Interneurons and Potentiates Excitatory Synaptic Transmission
}

\author{
Chris J. McBain, ${ }^{a}$ Timothy J. DiChiara, and Julie A. Kauer \\ Department of Neurobiology, Duke University Medical Center, Durham, North Carolina 27710
}

Based on responses to metabotropic glutamate receptor (mGluR) activation, we have characterized two distinct classes of interneuron in stratum (st.) oriens of the CA1 region of hippocampus. One type of interneuron was strongly excited by $1 S, 3 R$-aminocyclopentane dicarboxylic acid (ACPD), responding with a large inward current accompanied by increased baseline noise and prominent current oscillations. A second interneuron population responded with a modest inward current with no changes in baseline noise. These two classes of responses persisted in the presence of tetrodotoxin and antagonists of ionotropic glutamate and GABA receptors, suggesting that the inward currents result from mGluRs on the interneurons themselves. The two physiologically defined cell types correspond to two distinct morphological cell types in st. oriens/alveus, distinguished by very different patterns of local axonal connections. Large oscillatory inward current responses were recorded predominantly from an interneuron type whose axons heavily innervated st. lacunosum. The more modest inward current response was generally found in interneurons whose axons innervated the somata and proximal dendrites of CA1 pyramidal neurons. These differences in physiology and local circuitry imply that activation of mGluRs in st. oriens will cause very strong excitation of interneurons synapsing in st. lacunosum, and weaker excitation of interneurons innervating pyramidal cells at the soma and proximal dendrites. These data suggest that each interneuron population has a specific role in hippocampal function, and that mGluR activation will affect the local circuit differently for each interneuron type.

Metabotropic GluR activation also markedly enhanced the amplitudes of the evoked and spontaneous EPSCs received by all interneurons in the region, independent of changes in the postsynaptic holding current and with no change in the kinetics of the EPSC. In contrast to the enhancement of evoked and spontaneous EPSCs, miniature EPSCs recorded in the presence of tetrodotoxin were not increased. These

Received Aug. 31, 1993; revised Jan 12, 1994; accepted Jan. 27, 1994.

We thank Scott Douglas for performing the biocytin staining, Dr. Lawrence Katz for help with cell reconstruction and anatomy and for helpful discussion of the manuscript, and Drs. Steve Traynelis and Daniel Madison for generously supplying the acquisition and analysis programs. This work was supported by NIH Grant NS30500-01 (J.A.K.).

Correspondence should be addressed to Julie A. Kauer, Department of Neurobiology, Box 3209, Duke University Medical Center, Durham, NC 27710.

aresent address: Room 5A72, Building 49, NICHD-LCMN, 9000 Rockville Pike, Bethesda, MD 20892.

Copyright (C) 1994 Society for Neuroscience $0270-6474 / 94 / 144433-13 \$ 05.00 / 0$ data suggest that ACPD acts at a presynaptic site to potentiate the EPSC. Taken together, these results highlight an important modulatory role for metabotropic receptors located at sites both pre- and postsynaptic to CA1 st. oriens interneurons.

[Key words: metabotropic glutamate receptor, interneuron, hippocampus, synaptic transmission, ACPD, synaptic inhibition]

Hippocampal interneurons are predominantly GABAergic, and mediate both tonic inhibition of pyramidal cells and powerful feedforward and feedback IPSPs observed after stimulation of excitatory afferents onto pyramidal cells (Alger and Nicoll, 1982; Miles and Wong, 1984, 1987; Miles, 1991; McBain and Dingledine, 1993). Inhibitory synapses from hippocampal interneurons are located both on the dendrites of and on the cell bodies and initial segments of pyramidal cells, where they may depress and shunt the currents from cxcitatory synapses and play a decisive role in preventing or permitting action potential initiation (Lorente de No, 1934; Ramon y Cajal, 1968). Interneurons of CAl stratum oriens (st. oriens) receive excitatory innervation from both Schaffer collaterals of CA3 pyramidal cells and the recurrent collaterals of CA1 pyramidal cells. These neurons could therefore mediate both feedforward and feedback inhibition of pyramidal neurons (Lacaille et al., 1987). A single inhibitory interneuron may synapse on to over a hundred neighboring pyramidal cells; the modulation of excitability of a single st. oriens interneuron may therefore have widespread effects on the activity and output of the pyramidal cells it inhibits (for review, see Traub and Miles, 1992).

Although physiological and anatomical evidence points to the existence of several distinct types of interneuron, each potentially subserving different functions in the local circuit, the functional roles of different classes of interneurons are not well understood (Lacaille et al., 1987; Lacaille and Schwartzkroin, 1988; Lacaille and Williams, 1990; Lacaille, 1991; McBain and Dingledine, 1993). In particular, very little is known about the way different interneurons respond to neurotransmitters. One route for the selective modulation of interneurons is via the mGluR. High levels of mRNA for a metabotropic glutamate receptor, mGluR 1 , and immunostaining with an antibody for mGluR $1 \alpha$ have been reported in some neurons with somata in CAl st. oriens (Masu et al., 1991; Baude et al., 1993; Fotuhi et al., 1993). Pyramidal neurons and interneurons of the other CA 1 strata do not appear to express this receptor, suggesting a selective role for mGluRs on an as yet unidentified interneuron type.

Activation of metabotropic receptors, while using the same 
Table 1. Measurements of EPSCs

\begin{tabular}{llcc} 
& & & $1 S, 3 R-A C P D$ \\
& & Control & $(100 \mu \mathrm{M})$ \\
\hline Evoked EPSC & Rise time (msec) & ND & ND \\
& Decay time constant (msec) & $8.6 \pm 1.9(n=8)$ & $5.1 \pm 1.0$ \\
& Amplitude (pA) & $21.4 \pm 5.4$ & $66.0 \pm 27.9^{*}$ \\
Spontaneous EPSC & Rise time (msec) & $1.0 \pm 0.1(n=7)$ & $1.0 \pm 0.1$ \\
& Decay time constant (msec) & $5.6 \pm 0.4$ & $4.8 \pm 0.6$ \\
& Amplitude (pA) & $16.2 \pm 2.2$ & $38.3 \pm 7.1^{*}$ \\
Miniature EPSC & Frequency (Hz) & $2.6 \pm 0.8$ & $15.0 \pm 3.7^{*}$ \\
& Rise time (msec) & $1.4 \pm 0.1(n=14)$ & $1.1 \pm 0.1$ \\
& Decay time constant (msec) & $8.0 \pm 0.2$ & $6.2 \pm 0.7$ \\
& Amplitude (pA) & $12.8 \pm 1.2$ & $12.5 \pm 1.1$ \\
& Frequency (Hz) & $3.2 \pm 0.4(n=17)$ & $1.8 \pm 0.1^{*}$
\end{tabular}

$\mathrm{ND}$, rise time of the evoked EPSC was not determined.

* Significantly different from control $(p=0.05)$.

neurotransmitter as that for fast excitation (glutamate), results in very different effects on the neuron. These receptors couple through a GTP-binding protein to intracellular second messengers (Nicoletti et al., 1988; Schoepp et al., 1990; Miller, 1991). Second messengers are capable of producing long-lasting effects on cell excitability and metabolism. mGluR 1 receptors are coupled to activation of phospholipase $\mathrm{C}$ and thereby mediate release of $\mathrm{IP}_{3}$ and diacylglycerol (Houamed et al., 1991; Masu et al., 1991). In contrast to fast glutamatergic transmission, which can produce depolarization of a local region of the neuron on a rapid time scale, the release of second messengers after $m G$ GluR activation may potentially influence excitability over a much greater intracellular area, and on a much longer time scale.

We have investigated the possible roles and sites of action of metabotropic receptors by recording from interneurons of CA1 st. oriens. Neurons were filled with biocytin during recording, and we looked for correlations between the physiological responses to ACPD and the morphological characteristics of each cell. In addition, we examined the effects of ACPD on synaptic transmission, looking both at stimulated and spontaneous excitatory events. Based on the morphology of st. oriens interneurons, we also attempted to define physiologically neurons that may be synaptic targets of these interneurons. We find that mGluRs located both on presynaptic afferents and on st. oriens interneurons themselves modulate the activity of these interneurons. Our results show two separate populations of interneuron in st. oriens, with distinct responses to mGluR activation, and with quite different sites of axonal arborization, suggesting very different functional roles for these groups of cells in the local circuit. Wc have also found that $m$ GluR activation strongly enhances excitatory transmission onto all st. oriens interneurons, and this enhancement appears to result from modulation of activity of presynaptic neurons.

\section{Materials and Methods}

Interneuron recordings. Sprague-Dawley rats were killed by decapitation, following deep anesthesia using isollurane or ether. The brain was rapidly removed and placed in ice-cold $\mathrm{ACSF}(\mathrm{mM}): \mathrm{NaCl}, 130 ; \mathrm{NaHCO}_{3}$, 24; KCl, 3.5; $\mathrm{NaH}_{2} \mathrm{PO}_{4}, 1.25 ; \mathrm{CaCl}_{2}, 1.5 ; \mathrm{MgSO}_{4}, 1.5 ;$ glucose, 10 ; saturated with $95 \% \mathrm{O}_{2}, 5 \% \mathrm{CO}_{2}(\mathrm{pH} 7.4,307 \mathrm{mOsm})$. Sagittal slices $(200-250 \mu \mathrm{m})$ were cut from the middle third of the hippocampus in ice-cold ACSF. Following the slicing procedure, slices were held submerged in an incubation chamber $\left(28^{\circ} \mathrm{C}\right.$ for $1 \mathrm{hr}$ or longer) prior to their transfer to a submerged recording chamber. Most interneuron record- ings were made from animals between the ages of 19 and $24 \mathrm{~d}$, although some recordings were from older animals. During recording, slices were perfused at a rate of $1-2 \mathrm{ml} / \mathrm{min}$ with $\mathrm{ACSF}$ at $22-25^{\circ} \mathrm{C}$. All drugs were bath applied in known concentrations by direct addition to the perfusate. Phenol red was added to the drug-containing solution in order to monitor accurately the ingress and egress of the drug solution. Unless stated otherwise, all experiments were performed in the presence of $25-30 \mu \mathrm{M}$ picrotoxin to block $\mathrm{GABA}_{\mathrm{A}}$ currents.

Tight-seal (>1 G $\Omega$ ) whole-cell recordings (Hamill et al., 1981; Edwards et al., 1989) were obtained from the cell bodies of 69 interneurons in stratum oriens/alveus and four interneurons in stratum lacunosum of CAl hippocampus. Patch electrodes were fabricated from soft glass and were not fire polished. They had resistances of 3-8 $\mathrm{M} \Omega$ when filled with (mM) Cs methanesulfonate, 140; HEPES, $10 ; \mathrm{MgCl}_{2}, 2$ (buffered to $\mathrm{pH} 7.3$ with $\mathrm{CsOH}, 275-280 \mathrm{mOsm}$ ). In some experiments, ethylene glycol-bis( $\beta$-aminoethylether)- $N, N, N^{\prime}, N^{\prime}$-tetraacetic acid (EGTA), 0.6 mM; ATP. $\mathrm{Na}_{2}, 2 \mathrm{~mm}$; and GTP. $\mathrm{Na}, 0.3 \mathrm{~mm}$ were added to the internal solution. For experiments with the calcium ion chelator 1,2-bis(2-aminophenoxy)ethane- $N, N, N^{\prime}, N^{\prime}$-tetraacetic acid (BAPTA), we used the following internal solution (mM): Cs gluconate, 100; BAPTA, $30, \mathrm{MgCl}_{2}$, 2 ; ATP $\cdot \mathrm{Na}_{2}, 2$; GTP $\cdot \mathrm{Na}, 0.3$; HEPES, 10 . For current-clamp experiments, the following pipette solution was used (mM): K-gluconate, 100; $\mathrm{MgCl}_{2}, 5$; HEPES, 40; EGTA, 0.6; ATP. $\mathrm{Na}_{2}, 2$; GTP.Na, 0.3. In all experiments biocytin $(0.4-0.7 \%)$ was included in the electrode to permit post hoc identification and morphological characterization of the recorded cell.

The patch pipette was positioned under visual control within the stratum oriens/alveus of CA1; individual cells were visualized using a Zeiss water-immersion objective with Hoffman optics (overall magnification, $400 \times$ ). Breakthrough to the whole-cell mode was usually performed under current clamp in order to provide an initial evaluation of the passive membrane and action potential properties of the interneuron. Cells possessing an initial resting membrane potential more negative than $-50 \mathrm{mV}$ (mean $\pm \mathrm{SEM}=-55.4 \pm 0.6 \mathrm{mV}, n=42$ ) and overshooting action potentials were accepted. The internal dialysis of the cell by the $\mathrm{Cs}^{+}$-containing solution usually resulted in the cell stabilizing at a more positive potential within a few minutes of establishing whole-cell configuration. Interneurons were then voltage clamped at $-70 \mathrm{mV}$ unless stated otherwise in the text. CA1 st. oriens interneurons had input resistances ranging from 150 to $700 \mathrm{M} \Omega$ (mean, $337 \pm 16$ $\mathrm{M} \Omega, n=52$ ) at this holding potential. The measured membrane capacitance was $23 \pm 1.9 \mathrm{pF}(n=49)$. In experiments monitoring the interneuron response in current clamp the cell was held either at its resting potential or at $-60 \mathrm{mV}$ using intracellular current injection.

All currents were recorded with an Axoclamp 200A or Axoclamp 1D amplifier (Axon Instruments). Records were filtered at $1-5 \mathrm{kHz}(-3 \mathrm{~dB})$ and digitized at $3-30 \mathrm{kHz}$ on an 80486 computer. Signals were also stored unfiltered on video tape for later analysis.

To evoke excitatory postsynaptic currents (EPSCs), a bipolar stimulating electrode was placed in close proximity to the interneuron at the st. pyramidale/st. oriens border. EPSCs were evoked using a constant current stimulus isolator (World Precision Instruments, A360), $0.1 \mathrm{msec}$ 
A.
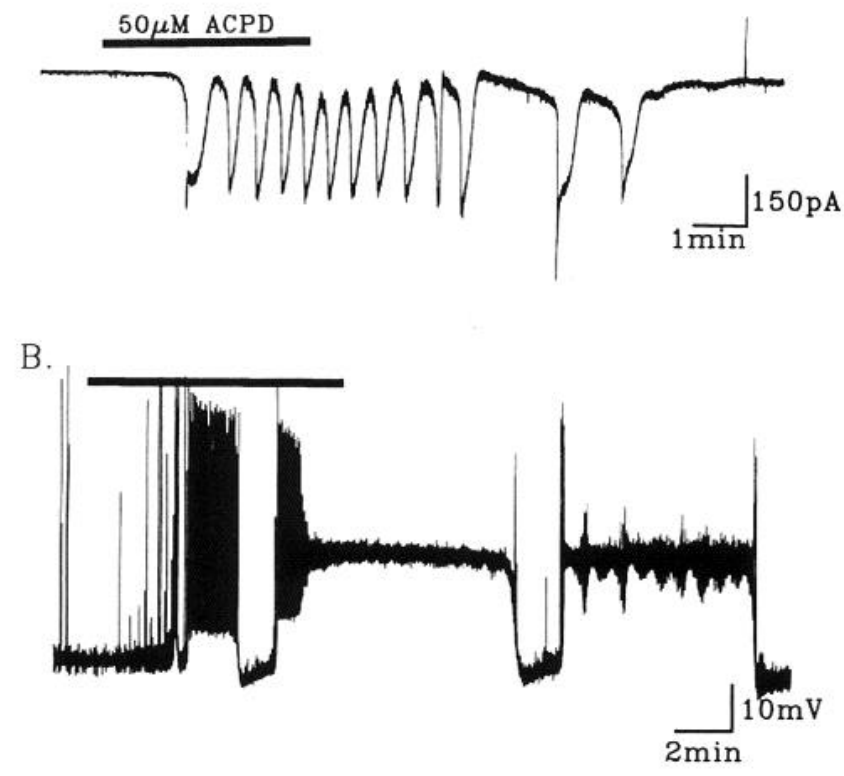

C.

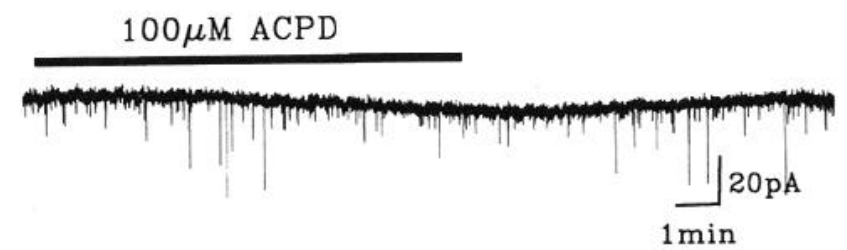

D

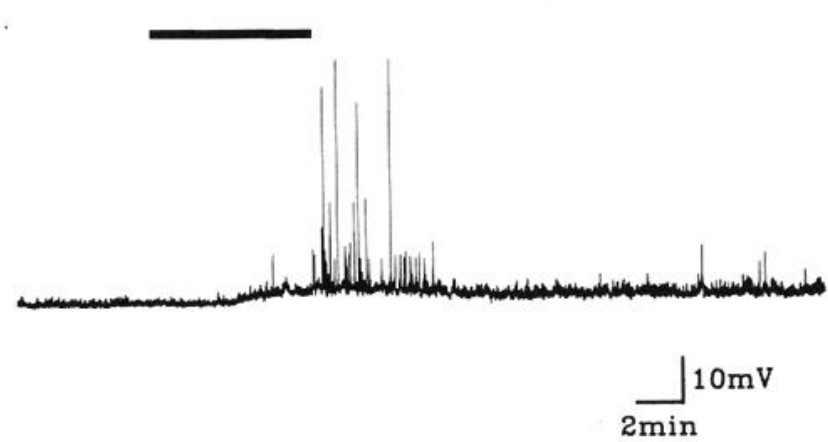

Figure 1. Two classes of response to ACPD can be recorded from st. oriens interneurons. $A$ and $C$ are recordings under voltage-clamp conditions; $B$ and $D$, under current-clamp conditions. One cell type responded to ACPD with a large oscillatory inward current, accompanied by increased baseline noise $(A)$. Under current-clamp conditions, the same cell underwent a slow depolarization/repolarization cycle with burst firing of action potentials $(B)$. The second cell type $(C$ and $D)$ responded with a much more modest inward current, and a slight depolarization accompanied by single action potentials. Action potentials are truncated due to sampling frequency.

at $0.1-0.2 \mathrm{~Hz}$. Stimulation of the afferent fibers often evoked multicomponent EPSCs. Only EPSCs with monotonic rising phases, however, were accepted for measurements reported in Table 1. The baseline was considered stable if the 1 min average EPSC amplitude was within $15 \%$ of that taken 10 min previously. Averaged EPSCs were constructed from at least 30 sequential events aligned at the foot of the rising phase of the stimulus artifact and averaged.

Individual spontaneous excitatory synaptic currents and miniature EPSCs (mEPSCs), recorded in the absence and presence of $1 \mathrm{~mm}$ tetrodotoxin, respectively, were identified visually and accepted for analysis if the mean current associated with the event was significantly different from that of an equivalent length of pre-event baseline. The 10-90\% rise time was calculated by linear regression over the appropriate data points. Measurements of the decay time constant of synaptic currents represent the mean of at least 100 events from each cell and were fitted by the sum of one or two exponential components (simplex algorithm, least squares criteria). The series resistance typically ranged from 5 to $50 \mathrm{M} \Omega$ (mean, $14 \pm 1.5 \mathrm{M} \Omega, n=49$ ). The amplitude of the EPSC was never more than $100 \mathrm{pA}$; thus, a series resistance of $20 \mathrm{M} \Omega$ would result in a DC series error no greater than $2 \mathrm{mV}$. The large current responses induced by ACPD likely resulted in significant series resistance error. Membrane potentials were not corrected for these errors. Junction potentials were typically about $3 \mathrm{mV}$; holding potentials reported in the text have been corrected.

All data are represented as the mean \pm standard error of the mean. Where appropriate, an unpaired Student's $t$ test was performed.

$C A 1$ and CA3 pyramidal cell recordings. Whole-cell recordings were made from pyramidal neurons located in stratum pyramidale of $\mathrm{CA} 1$ and CA3. Solutions were identical to those used in the interneuron recordings except on occasion, the solution perfusing the slice contained $2.5 \mathrm{~mm} \mathrm{CaCl}_{2}$ and $2.5 \mathrm{~mm} \mathrm{KCl}$. This solution did not appear to affect the obtained results. To record spontaneous IPSCs, the following pipette solution was used to increase intracellular $\mathrm{Cl}^{-}$concentrations (mM): Cs gluconate, $60 ; \mathrm{CsCl}, 40 ; \mathrm{MgCl}_{2}, 2 ;$ ATP $\cdot \mathrm{Na}_{2}, 2 ; \mathrm{GTP} \cdot \mathrm{Na}, 0.3 ; \mathrm{HEPES}$, 40.

Morphological characterization. Following all recordings, intact slices were fixed in a $4 \%$ solution of paraformaldehyde overnight. After immersion in 30\% sucrose in PBS, slices were cut into 50-70 $\mu \mathrm{m}$ sections on a freezing microtome. Biocytin staining was processed using an avidin-HRP reaction (Vectastain ABC Standard Kit). The biocytin reaction was enhanced using a solution containing $\mathrm{NiNH}_{4} \mathrm{SO}_{4}(1 \%)$ and
$\mathrm{CoCl}_{2}(1 \%)$. This step was essential for the complete visualization of the interneuron axon. The slices were then mounted and dehydrated on gelatin-coated glass slides for camera lucida reconstruction and photography.

Drugs used were $1 S, 3 R$-aminocyclopentane dicarboxylic acid (ACPD), $(2 S, 3 S, 4 S)$ - $\alpha$-(carboxycyclopropyl)-glycine (L-CCGI), L-2-amino-3phosphonopropionate (L-AP3), quisqualate, and 6,7-dinitroquinoxaline-2,3-dione (DNQX) (Tocris Neuramin); picrotoxin, biocytin, and tetrodotoxin (TTX) (Sigma); and D-2-amino-5-phosphonovalerate (AP5; Cambridge Research Biochemicals).

\section{Results}

1S,3R-ACPD triggers an inward current and increased baseline noise in CAl st. oriens interneurons

The application of ACPD produced two distinct types of responses. In 36 of 52 interneurons tested, application of ACPD (50-100 $\mathrm{mm}$ ) rapidly elicited a biphasic response upon entry of drug into the recording chamber. A small inward current of 10$30 \mathrm{pA}$ was activated which was not associated with any change in baseline noise. After several minutes, ACPD activated a much larger, rapidly developing inward current (mean, $-221 \pm 26$ pA, $n=36$ ) (Figs. $1 A, 2 A$ ), accompanied by a dramatic increase of baseline noise. In the continued presence of drug, the inward current slowly declined to a steady state level or returned to baseline levels. In 15 of 36 cells, this late phase was accompanied by slow oscillations of $0.03-0.1 \mathrm{~Hz}$ (Fig. 1A). Although the inward current ended within minutes after return to drug-free perfusate, the associated baseline noise often did not return to control values, for periods up to several hours.

In four cells, ACPD was tested at $3 \mu \mathrm{M}, 10 \mu \mathrm{M}, 30 \mu \mathrm{M}$, and $100 \mu \mathrm{M}$. The large inward current was only observed at 30 and $100 \mu \mathrm{M}$. The response to $30 \mu \mathrm{M}$ ACPD is $>85 \%$ of the maximum response; therefore, we have used $100 \mu \mathrm{M}$ to remove any ambiguity about interneurons that failed to respond with a large inward current (see below). In two cells, the potent mGluR 
A. $\quad 100 \mu \mathrm{M}$ ACPD

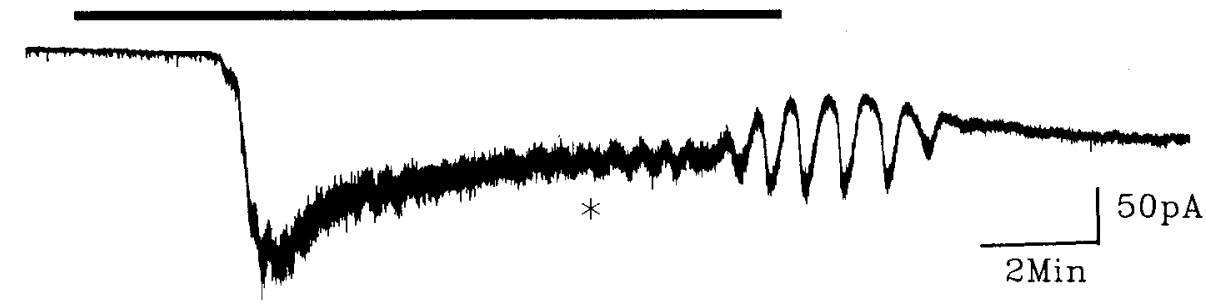

B.

Figure 2. The large inward current and accompanying baseline noise are insensitive to TTX $(1 \mu \mathrm{M})$, demonstrating that they do not result from synaptic currents. A, Application of $100 \mu \mathrm{M}$ ACPD in the presence of $1 \mu \mathrm{M}$ TTX produces a large inward current. $B$ and $C$, Data from $A$ taken prior to ACPD and from the region marked with an asterisk (*) are shown on an expanded time base and at higher gain to highlight the increased baseline noise after ACPD.

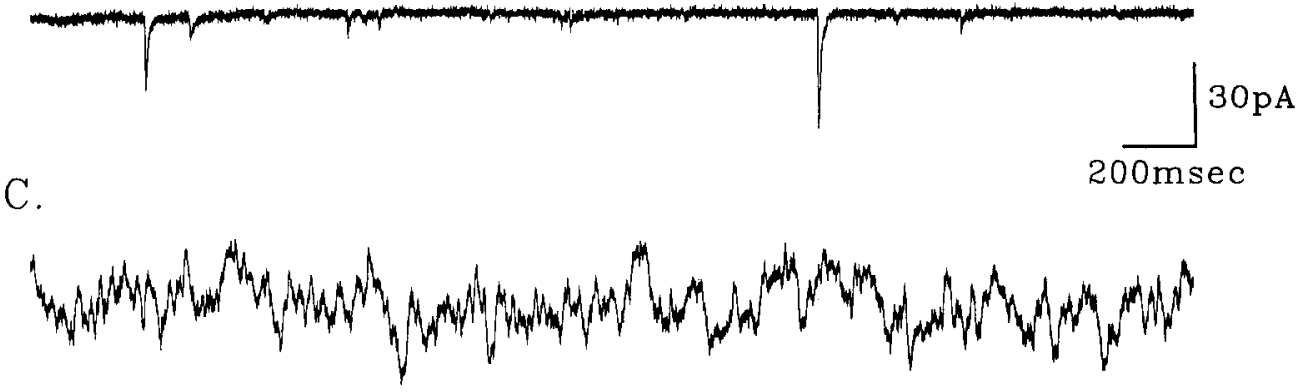

agonist quisqualate $(2 \mu \mathrm{M})$ was bath applied in the presence of $20 \mu \mathrm{M}$ DNQX to block ionotropic AMPA receptors. The response was identical to that seen with $100 \mu \mathrm{M}$ ACPD (inward current --125 and $-275 \mathrm{pA}$ ). In two additional cells, the selective metabotropic receptor agonist L-CCGI was applied at $100 \mu \mathrm{M}$. Again, the response was identical to that seen in ACPD (inward current $=-250$ and $-500 \mathrm{pA}$ ).

Of the remaining 16 st. oriens interneurons tested, four cells showed no response to ACPD, while the remaining 12 exhibited only a small inward current (mean, $-13 \pm 3 \mathrm{pA}, n=12$; Fig. $1 C)$, resembling the initial phase of the ACPD response described above. Oscillations and changes in baseline noise were not associated with this response even when cells were exposed to ACPD for up to $30 \mathrm{~min}$.

In current-clamp recordings, where changes in cell voltage are unrestrained, we also observed two distinct types of response to $\mathrm{ACPD}(n=6$; Fig. $1 B, D)$. Because st. oriens interneurons fire spontaneous action potentials at their resting membrane potential, cells were held slightly hyperpolarized (1-2 $\mathrm{mV})$ at $-60 \mathrm{mV}$, by injecting current. After a $2-5 \mathrm{~min}$ delay, three cells displaying the large oscillatory current under voltage clamp responded with an abrupt depolarization of $\sim 20-30 \mathrm{mV}$. The depolarization was accompanied by high-frequency action potential firing, which either persisted for the entire depolarizing episode or rapidly inactivated, probably due to voltage-dependent inactivation of sodium channels (Fig. $1 B$ ). In each of these three cells, the depolarization did not persist despite the continued presence of the drug, but instead, over a period of several minutes the cells exhihited episodes of spontaneous alternating depolarization and repolarization (Fig. $1 B$ ). On removal of drug, the depolarizing/repolarizing cycle continued for several minutes before the membrane potential returned to control levels.

In contrast, interneurons that responded with only a small inward current under voltage clamp, under current clamp depolarized by only $1-2 \mathrm{mV}(n=3$; Fig. $1 D)$. This was associated with a slow repetitive firing of single action potentials (0.3-1 $\mathrm{Hz}$ ). No depolarization/repolarization cycles were observed in these cells.

\section{Dependence of the large oscillatory response on intracellular cyclic nucleotides}

After a single challenge with ACPD, those interneurons responding with the large oscillatory current did not respond on second and subsequent challenges $(n=5)$. However, if ATP and GTP were included in the patch-pipette internal solution, the response could be induced with every trial $(n-31)$. This suggests that the underlying mechanism may require activation of a GTPbinding protein and demonstrates that this response results from postsynaptic mechanisms in the recorded cell. In subsequent experiments, ATP and GTP were routinely included in the intracellular solutions.

\section{The oscillatory current persists after blockade of synaptic transmission}

The increase in baseline noise initially suggested that part of the inward current induced by ACPD resulted from an increase of synaptic current. However, blockade of voltage-dependent $\mathrm{Na}^{+}$ currents with tetrodotoxin (TTX; $1 \mu \mathrm{M}$ ), to prevent action potential-driven synaptic transmission, did not prevent the activation of the large inward current by ACPD (mean inward current, $-299 \pm 44 \mathrm{pA}, n=16$; Fig. $2 A$ ). The associated increase in baseline noise persisted in the presence of TTX (and picrotoxin) (Fig. 2B,C).

To address the possibility that the increase in current and noise resulted from an increase in miniature EPSCs, we blocked glutamate receptors responsible for fast synaptic transmission. Neither D-AP5 (100 $\mu \mathrm{M}, n=3)$ nor DNQX $(20 \mu \mathrm{M}, n=3)$ (NMDA and AMPA receptor blockers, respectively) affected the large inward current or the associated baseline noise, even though DNQX (in the presence of picrotoxin) completely abol- 
ished all spontaneous synaptic activity at a holding potential of -70 to $-80 \mathrm{mV}$. Inclusion of L-AP3 ( $1 \mathrm{~mm}, n=3)$ also did not prevent the initiation or maintenance of the large inward current. The presence or absence of picrotoxin did not affect the large oscillatory current $(n=6)$.

These data indicate that the inward current and increased noise are independent of AMPA or NMDA receptor activation by increased ambient levels of glutamate or a related excitatory amino acid receptor agonist. These data also demonstrate that the effects of $\Lambda C P D$ result from activation of metabotropic glutamate receptors on the interneurons themselves, rather than on afferent fibers presynaptic to these cells.

\section{The large inward current is dependent on intracellular $\mathrm{Ca}^{2+}$}

The oscillatory nature of the large inward current is reminiscent of $\mathrm{Ca}^{2+}$-dependent oscillations in other cell types (for review, see Henzi and MacDermott, 1992). We therefore investigated the possible involvement of intracellular $\mathrm{Ca}^{2+}$ in the large inward current response by including the fast $\mathrm{Ca}^{2+}$ chelator BAPTA ( $30 \mathrm{~mm})$ in the intracellular solution. In 7 of 11 interneurons tested we were unable to provoke any response to ACPD. However, in four cells, the inward current response was observed and was some 10-fold less than without BAPTA (mean, - 23.7 $\pm 8.5 \mathrm{pA}, n=4)$. In addition, inclusion of BAPTA removed the initial fast component of the inward current. The small current remaining in $30 \mathrm{~mm}$ BAPTA was reminiscent of the usual response since the increase in baseline noise persisted, albeit to a lesser degree.

\section{The large inward current is not carried by voltage-gated ion channels}

We observed that the inward current was accompanied by a modest incrcase in membrane conductance measured with brief voltage pulses (conductance increase in $100 \mu \mathrm{M} \mathrm{ACPD,} 137 \pm$ $14 \%, n=4)$. To identify the source of the current, we tested voltage-dependent ion channel blockers. The failure of TTX to block the inward current ruled out voltage-gated $\mathrm{Na}^{+}$channels $(n=16)$. The presence of $\mathrm{Cs}^{+}$in the internal solution makes it very unlikely that the inward current results from blockade of a standing $\mathrm{K}^{\prime}$ current. Addition of $500 \mu \mathrm{M}$ to $1 \mathrm{~mm} \mathrm{CoCl}_{2}$ also had no effect on either initiation or the maintenance of the large inward current and oscillatory response, suggesting that influx of calcium ions through voltage-gated calcium channels is not involved $(n=3)$.

In summary, the large inward current and increase in noise seen with ACPD are not attenuated by blocking voltage-gated $\mathrm{Na}^{+}, \mathrm{Ca}^{2+}$, or $\mathrm{K}^{+}$currents, or by blocking fast excitatory or inhibitory synaptic transmission. Furthermore, an involvement of $\mathrm{Cl}^{-}$currents can be ruled out since the inward current did not reverse over the range -30 to $-100 \mathrm{mV}\left(E_{\mathrm{Cl}^{-}} \sim-80 \mathrm{mV}\right)$.

\section{The voltage dependence of the large inward current}

The increased membrane conductance during the inward current suggested that at least part of the current was caused by the opening of membrane channels. One remaining candidate to mediate the ACPD-induced response is a $\mathrm{Ca}^{2+}$-activated, nonselective cation channel. If the inward current were carried by a nonselective cation channel, we would expect the current to reverse polarity near $0 \mathrm{mV}$. Due to the large increase in synaptic noise and the desensitization of the response over time, it was difficult to get reliable measurements of the current-voltage relationship. However, in three interneurons it was possible to
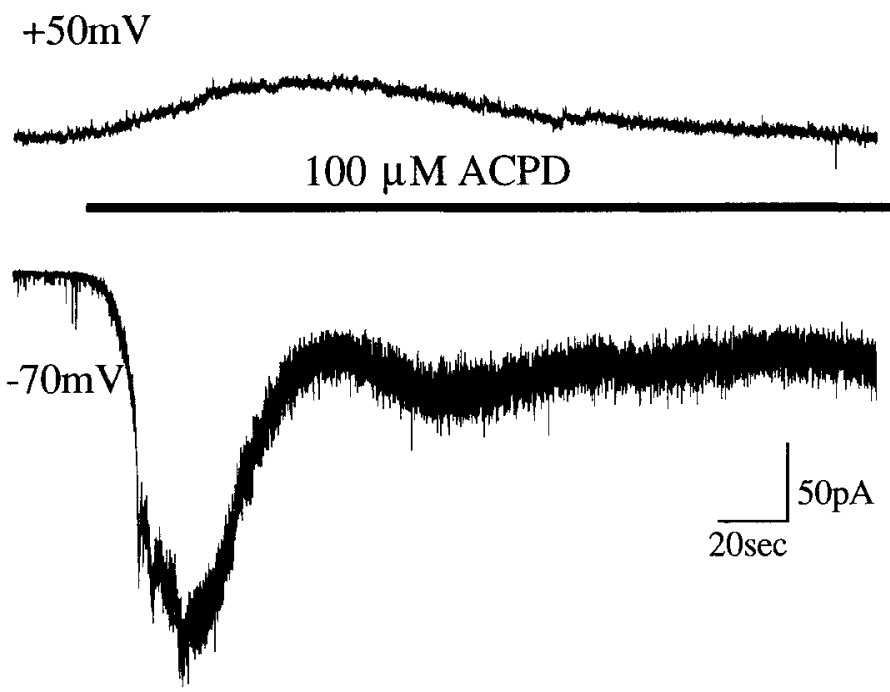

Figure 3. The inward current induced by ACPD at $-70 \mathrm{mV}$ reverses but is much smaller when the cell is held at $+50 \mathrm{mV}$. ACPD $(100 \mu \mathrm{M})$ was applied for $5 \mathrm{~min}$ when the cell was held first at $-70 \mathrm{mV}$, then at $+50 \mathrm{mV}$. TTX $(1 \mu \mathrm{M})$ was present throughout.

voltage clamp the current induced by ACPD at positive voltages (Fig. 3). At a holding potential of $+50 \mathrm{mV}$, an outward current could be elicited, but it was considerably smaller than that recorded at $-70 \mathrm{mV}(+37 \pm 9.4 \mathrm{vs}-213 \pm 48 \mathrm{pA}, n=3)$. In one cell, no change in holding current was recorded during bath application of ACPD at $+50 \mathrm{mV}$, although at $-70 \mathrm{mV}$, a -500 pA inward current was induced by ACPD both before and following the depolarization to $+50 \mathrm{mV}$.

The reversal potential of spontaneous and evoked EPSCs was $\sim 0 \mathrm{mV}$, suggesting that the steady state voltage control was not compromised during the addition of the drug. The currents generated at $+50 \mathrm{mV}$ were not accompanied by the large baseline noise increase seen at negative holding potentials.

These data suggest that although a component of the current may be carried through a nonselective cation channel, most of the current induced in ACPD cannot be accounted for through this mechanism. Having eliminated synaptic currents and voltage-dependent currents as potential mediators of the ACPD response, the most likely source of the remaining inward current and noise is an $\mathrm{Na}^{+} / \mathrm{Ca}^{2+}$ exchanger in the plasma membrane (see Discussion).

\section{Morphology of $\mathrm{CA1}$ st. oriens interneurons}

From 69 recordings we successfully stained 55 cells with biocytin. The stained interneurons fell into two major groups.

The first cell type was a vertically oriented interneuron (15 of 55 cells) (Fig. $4 A$ ), similar to those previously described by Lacaille and co-workers (Lacaille et al., 1987; Lacaille and Williams, 1990). These cells were located in the superior zone of the st. oriens, close to the alveus border. Somata $(20-50 \mu \mathrm{m}$ in diameter) of these cells were usually multipolar and vertically oriented, with dendritic processes (usually two to six) projecting both horizontally and vertically throughout st. oriens. Dendrites also passed over st. pyramidale and projected into st. radiatum, often reaching as far as st. lacunosum. The axons of these cells ramified locally within st. oriens, and formed a dense branching plexus in st. pyramidale, generally extending for long distances $(\sim 400 \mu \mathrm{m})$ along st. pyramidale (Fig. $4 A$ ). Although part of the 


\section{A}

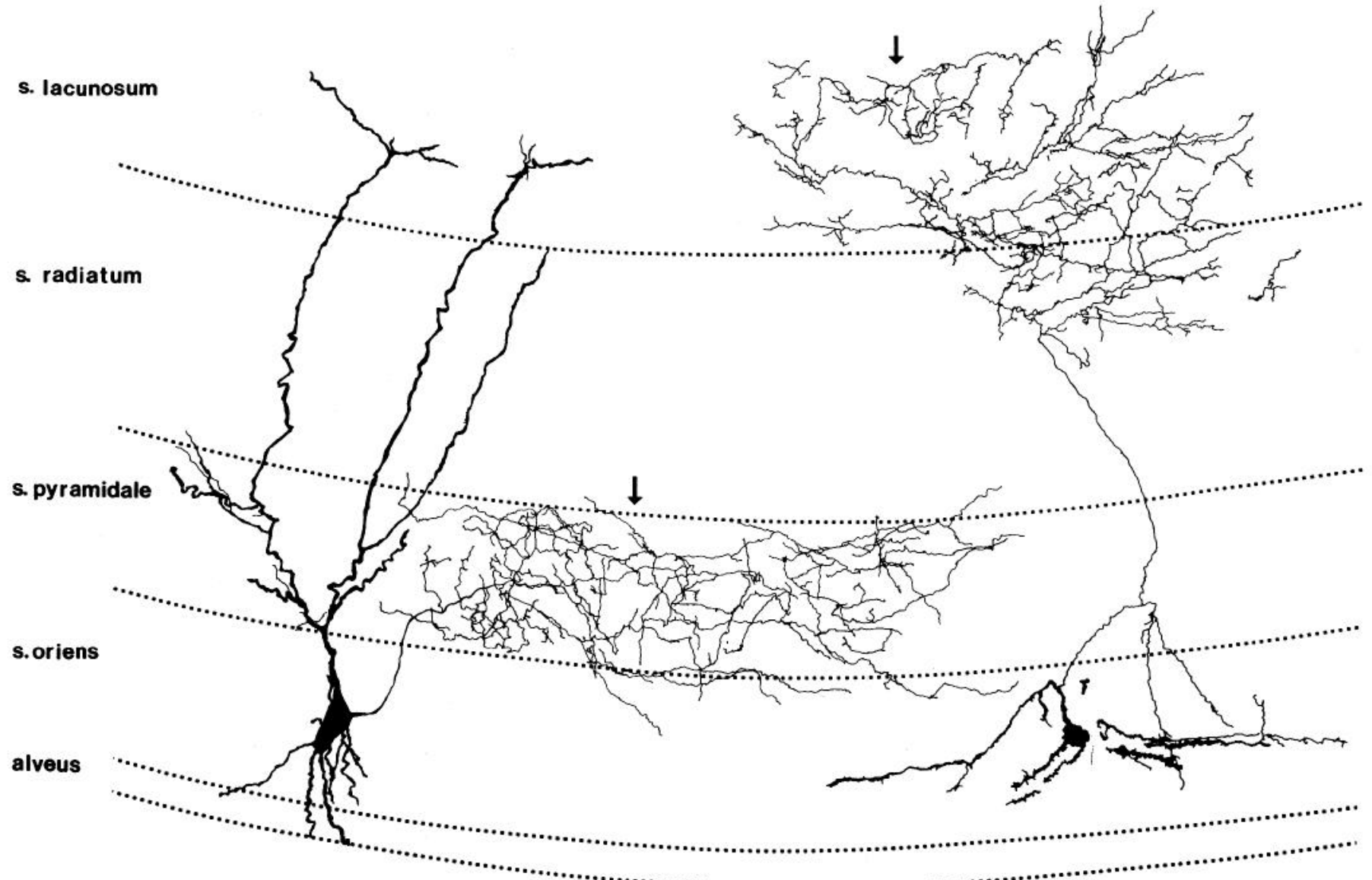

B

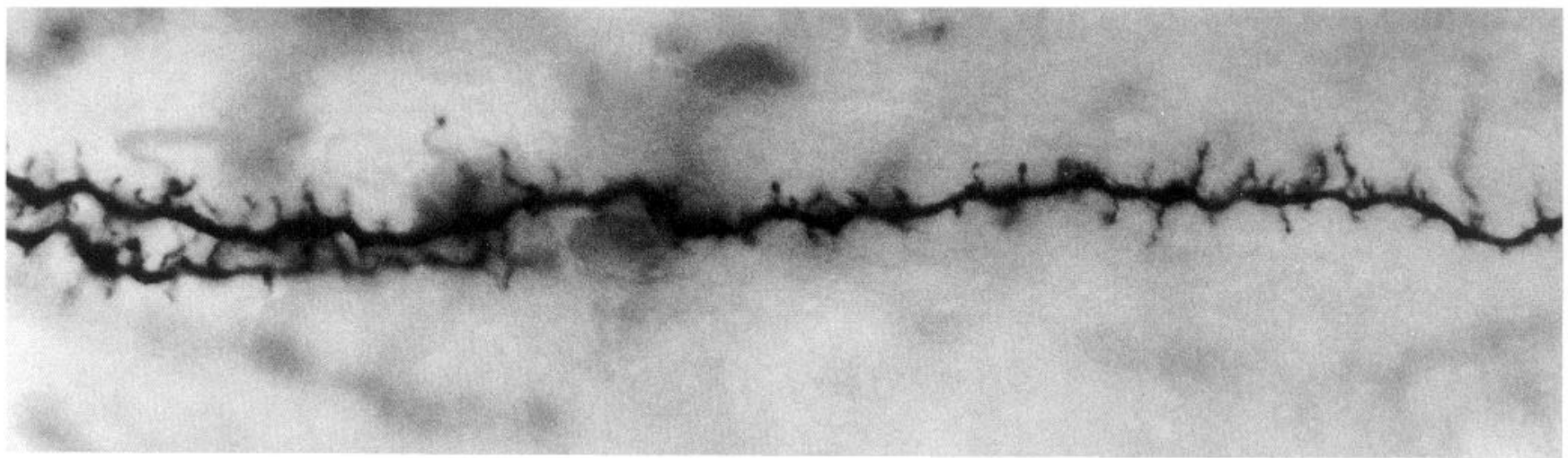

Figure 4. A, Camera lucida reconstructions of two st. oriens interneurons demonstrating the two major morphological cell classes. The cell on the left has vertically oriented dendrites and its axon heavily innervates st. pyramidale (arrow). The cell on the right has horizontally oriented dendrites and sends its axon to st. lacunosum (arrow). Cells were reconstructed from slices $250 \mu \mathrm{M}$ thick. $B$, The spiny dendrite of a st. oriens interneuron. The interneuron was filled with biocytin during recording. Magnification, $2800 \times$. 
axons entered st. radiatum, axons never projected to st. lacunosum. This morphology suggests a powerful inhibitory role for this cell type at the cell body and proximal dendrites of pyramidal cells.

The cell bodies of the second interneuron type $(n=36)$ resided in the superior zone of st. oriens. These cells possessed large cell bodies $(20-70 \mu \mathrm{m})$ that differed from the first type of interneuron in that they were usually horizontally oriented, that is, parallel to the pyramidal cell layer. The thick varicose dendrites of this cell type were few and seldom branched. These dendrites coursed horizontally, often for several hundred micrometers within st. oriens and alveus, but never crossed into st. pyramidale or st. radiatum. These interneurons correspond to superior zone cells originally described by Ramon y Cajal (1968). We were able to characterize the axons of 14 of these cells. Surprisingly, the axons of these cells crossed st. pyramidale and ran through radiatum to st. lacunosum, where they formed a highly branching plexus, covering an area of several hundred micrometers within st. lacunosum. This morphology matches that of somatostatin-containing cells of st. oriens (Naus et al., 1988; Schwartzkroin et al., 1990; Baude et al., 1993). After passing into st. radiatum, the axons of some of these cells send a "recurrent" axonal branch back across st. pyramidale and into st. oriens (see Fig. $4 A$ ). This recurrent branch formed only a minor part of the axon ramification.

We rarely encountered a third cell type (4 of 55 ), which had cell bodies located in the alveus near the epithelial border. This cell type possessed short, horizontal dendrites that remained within the alveus and never projected into st. pyramidale. In three cells with well-stained axons, the axons ramified locally in st. oriens or pyramidale.

Occasionally, recorded cells were actually pyramidal neurons ectopically located in st. oriens. These cells possessed the classic morphology of pyramidal neurons with highly divergent apical and basilar spiny dendrites. The data from cells identified as pyramidal were not included in this study. The presence of ectopically located pyramidal neurons stresses the importance of post hoc anatomical identification of all cells from which recordings were made. We rarely recorded from cells identified as pyramidale or basket-like interneurons as described by Lacaille (1991). However, these cells tend to lie close to or within the st. pyramidale, while our recordings were made at the superior-inferior border of st. oriens/alveus.

The slices processed for morphological characterization were $200-250 \mu \mathrm{m}$ thick (along the longitudinal axis of the hippocampus). In many cases axons were detected at both cut edges of the original slice, suggesting that the axonal projections we have mapped are an underestimate of their true extent.

Dendritic spines have been reported on st. oriens interneurons (Ramon y Cajal, 1968; Pitkanen and Amaral, 1993) and hilar interneurons (Livsey and Vicini, 1992). We observed spines on all cell types (Fig. $4 B$ ) (6 of 15 well-filled vertically oriented cells had spines, while 17 of 36 horizontal cells were spiny). However, not all cells were spiny, and in some vertically oriented neurons, dendrites in st. oriens were spiny, while dendrites in st. radiatum were not. There was a high divergence of dendritic spine morphology. When compared with spines on CAl pyramidal cell dendrites, the spines on all types of interneurons were stubby or thorn-like, usually without classical spine heads common to pyramidal neurons. CA1 pyramidal cell dendrites are also more densely covered with spines than even the most spiny st. oriens interneuron. On occasion, we observed long wisp-like spines often $10-20 \times$ times the length of those spines identified on CAl pyramidal neurons. These long spines were reminiscent of those observed on parvalbumin-containing basket cells described by Pitkanen and Amaral (1993). We found no correlation between the age of animals used in this study and the presence or absence of spines.

\section{Comparison of the morphological and pharmacological properties of the cells}

A definite correlation emerged between the responses of st. oriens interneurons to ACPD and their morphological characteristics. All cells with horizontally oriented somata, with dendrites located exclusively in st. oriens/alveus, and with axons extending into st. lacunosum responded to ACPD with a large inward current $(n=16)$ and often with an oscillatory response $(n=6)$. Of the remaining 20 cells with similar somatic and dendritic morphologies but whose axons we were unable to identify, 19 also responded with the large oscillatory response. In contrast, 11 of 15 cells whose dendrites crossed over st. pyramidale into st. radiatum and whose axons ramified throughout st. oriens, pyramidale, and radiatum responded to ACPD with only a small inward current and no increase in the baseline noise. In summary, we have identified two distinct groups of interneurons in st. oriens based on both pharmacological and morphological criteria.

\section{ACPD potentiates the excitatory postsynaptic current on st. oriens interneurons}

We next investigated the effects of metabotropic receptor activation on EPSCs received by the st. oriens interneuron population. Electrical stimulation at the st. pyramidale/st. oriens border reliably evoked EPSCs in most interneurons tested. EPSCs were small in amplitude (Table 1) and apparently "failed" often, suggesting that a small number of afferent fibers were activated to evoke the response. In general, multicomponent EPSCs were evoked, suggesting that these EPSCs did not originate from a single synaptic site. In eight of nine interneurons tested, addition of ACPD markedly increased the amplitude of the evoked EPSC (Fig. 5, Table 1). The effect was independent of changes in holding current or the presence or absence of the oscillatory response described above, and occurred in cells of both morphological groups described above (five horizontal cells, two vertical cells, and one unidentified cell). The potentiation of the EPSC developed immediately upon entry of ACPD into the recording chamber, well before the onset of the large inward current.

The potentiating effect of $1 S, 3 R$-ACPD persisted for the duration of the drug application and reversed following removal of the drug, although often a long washout period (20-30 min) was required for a return to baseline values. The persistent potentiation reported at the $\mathrm{CA} 3 / \mathrm{CA} 1$ pyramidal cell synapse was not observed in these cells (Bortolotto and Collingridge, 1993).

\section{Enhancement of the EPSC by ACPD involves a presynaptic mechanism}

The enhancement of the evoked EPSC could result either from a presynaptic mechanism, such as depolarization of presynaptic neurons or enhanced transmitter release, or from a postsynaptic mechanism, such as an increased number of available AMPA receptors. We sought to clarify the locus of activity by examining 

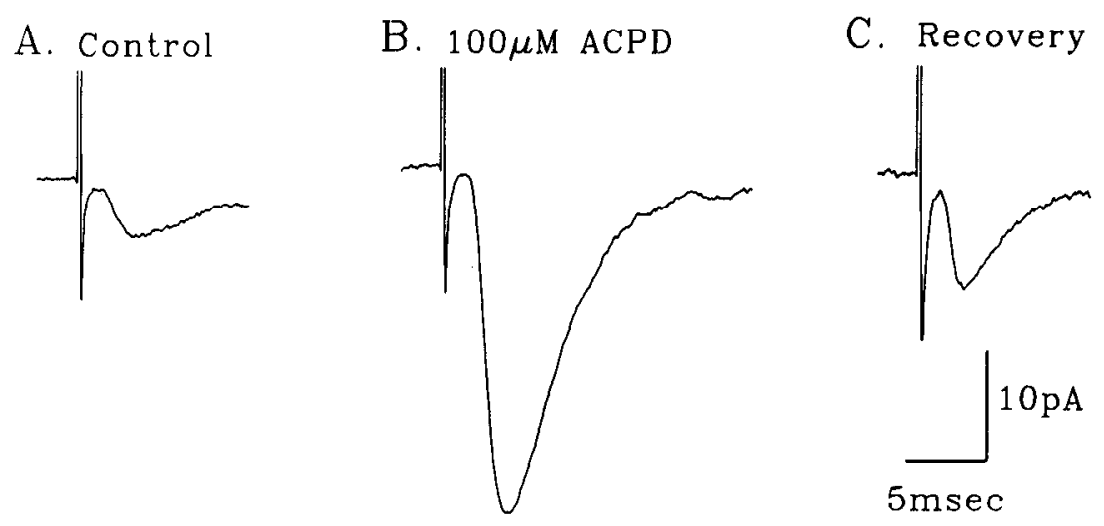

Figure 5. ACPD potentiates EPSCs recorded from a st. oriens interneuron. EPSCs were evoked at $0.1 \mathrm{~Hz}$ with a stimulating electrode placed at the st. pyramidale/st. oriens border about 200 $\mu \mathrm{m}$ from the interneuron cell body. $\operatorname{ACPD}(100 \mu \mathrm{M})$ as bath applied for 10 min. EPSCs $(t o p)$ are the averages of 30 responses taken before, during, and 20 min after ACPD application.

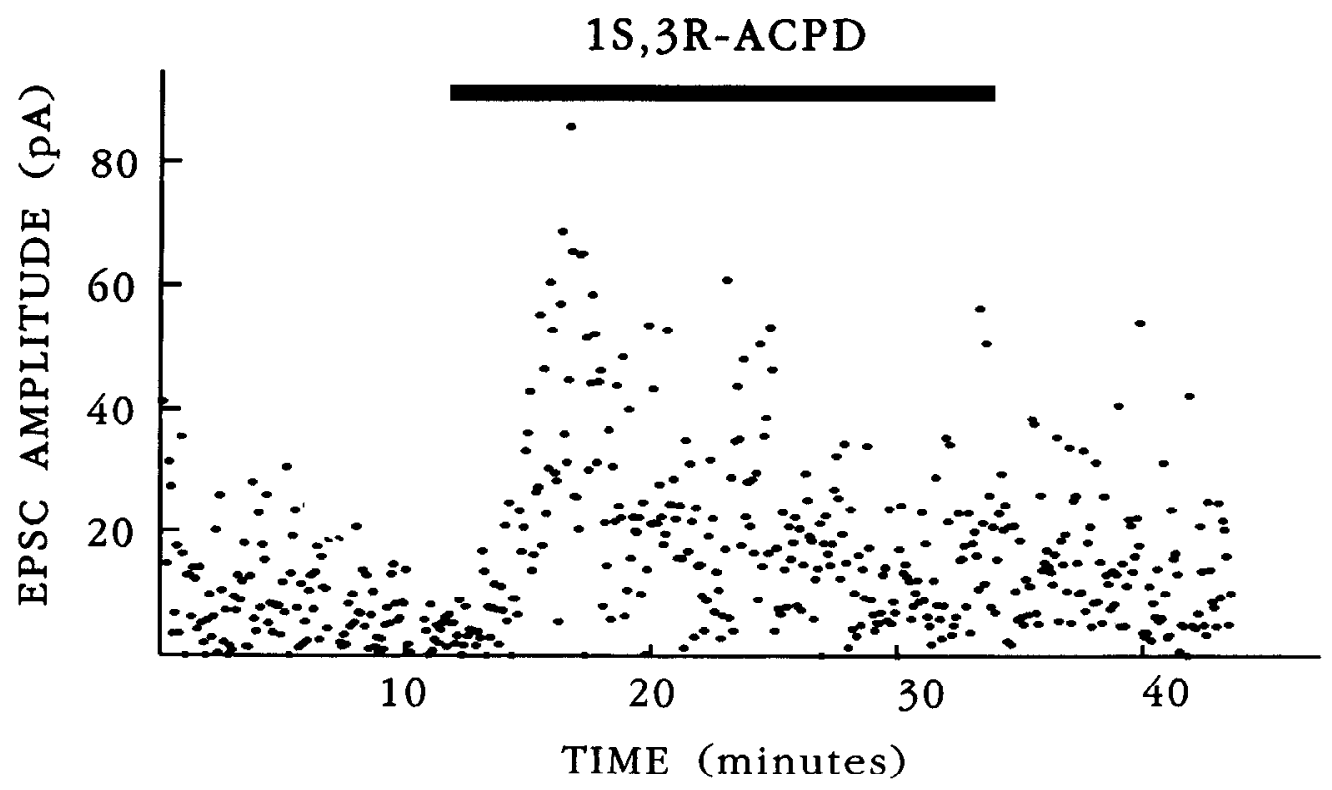

the amplitude and frequency of spontaneous EPSCs. Like evoked EPSCs, the amplitudes of spontaneous EPSCs were potentiated in $\Lambda$ CPD $(n-7)$ (Fig. 6, Table 1). Furthermore, the frequency of spontaneous EPSCs was dramatically increased, from $2.6 \pm$ $0.9 \mathrm{~Hz}$ to $15.0 \pm 3.7 \mathrm{~Hz}(n=6)$ (Fig. $6 A, B$; Table 1$)$. In cells responding to $A C P D$ with a large inward current, the increase in baseline noise prevented accurate measurements of spontaneous EPSCs after onset of the inward current. Thus, the enhancement of the EPSC amplitude and frequency we report may underestimate the actual changes. Both the amplitude potentiation and the increased frequency of spontaneous EPSCs reversed after washing for approximately $20 \mathrm{~min}$

The effects of ACPD on EPSC frequency and amplitude were independent of the magnitude of inward current or the presence/ absence of the oscillatory response, and potentiation of the EPSC occurred several minutes prior to the onset of the large inward current. These results suggest two distinct loci of action for ACPD. In addition, the increase in spontaneous EPSC frequency demonstrates a presynaptic action of ACPD that may be responsible for enhancement of the evoked EPSC.

We next examined the effects of ACPD on miniature EPSCs recorded in the presence of TTX $(1 \mu \mathrm{M})$ to determine whether an increased postsynaptic sensitivity to glutamate contributes to the increased EPSC amplitude. In the presence of TTX, ACPD did not increase either the mean amplitude or frequency of miniature EPSCs; in fact, frequency was significantly depressed (Table 1). These data suggest that the enhanced EPSC results solely from ACPD action on the presynaptic afferents, and show that an active presynaptic terminal is essential for the enhanced EPSC.

The origin of the presynaptic input causing the st. oriens interneuron EPSC enhancement

The observed effects on evoked and spontaneous EPSCs could be explained by depolarization of either $\mathrm{CA} 1$ or CA3 pyramidal cells, which make synaptic contact with these interneurons. Addition of ACPD slightly depolarized CA1 pyramidal neurons (0-3 mV; mean, $1.67 \pm 0.38 \mathrm{mV}, n=6)$; cells held under voltage clamp had inward currents of 10 to $30 \mathrm{pA}$ in response to ACPD (mean, $-14 \pm 2.5 \mathrm{pA}, n=6$ ). ACPD strongly depolarized CA3 pyramidal cells and resulted in spontaneous action potential firing (mean depolarization, $17.3 \pm 1.4 \mathrm{mV}, n=7$ ). Thus, pyramidal cells in both regions are excited by ACPD as previously reported (Stratton et al., 1989; Desai and Conn, 1991; $\mathrm{Hu}$ and Storm, 1991).

\section{CAI pyramidal cells are one synaptic target of the st. oriens interneurons}

Based on our anatomical data showing that axons of st. oriens interneurons arborize in st. pyramidale or in st. lacunosum, and 
A. Control

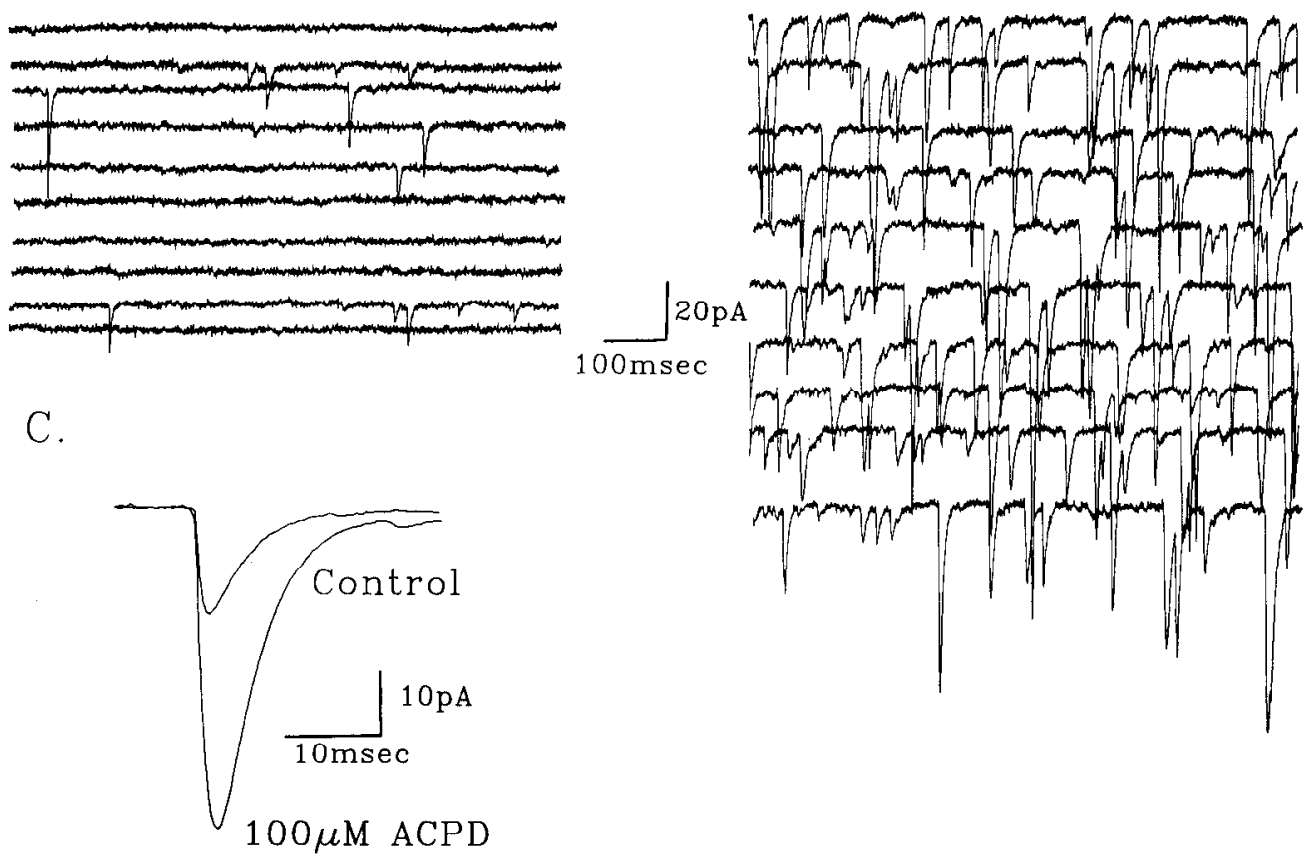

B. $100 \mu \mathrm{M}$ ACPD

Figure 6. Spontaneous EPSCs increase in both frequency and amplitude in $100 \mu \mathrm{M}$ ACPD. Ten consecutive traces arc shown before $(A)$ and 1 min after $(B)$ bath application of ACPD. $C$, The average of 40 EPSCs before and $1 \mathrm{~min}$ after ACPD application. on physiological results demonstrating that both interneuron types are excited by ACPD, we predicted that in the presence of ACPD, spontaneous IPSCs on the pyramidal cells should increase. In recordings of spontaneous IPSCs from CAl pyramidal neurons during blockade of glutamatergic fast synaptic transmission, ACPD strongly increased the frequency of spontaneous IPSCs (five of five cells) (Fig. 7). Picrotoxin, a GABA receptor antagonist, entirely abolished these spontaneous events. The increase in IPSCs could reflect activation of both classes of interneuron, or simply of those that project to st. pyramidale, whose input would be expected to dominate our somatic recordings.

\section{St. lacunosum interneurons are not a target of st. oriens interneurons}

Those cells whose axons ramify distally in st. lacunosum could make synaptic contact with a cell population other than $\mathrm{CAl}$ pyramidal neurons. To test this idea, we made recordings from interneurons located deep in st. lacunosum. In the presence of DNQX $(20 \mu \mathrm{M})$ and the absence of picrotoxin we observed no increase in the IPSC frequency in four of four st. lacunosum interneurons. These data suggest that st. lacunosum interneurons are not a major innervation target of the st. oriens interneurons. The most likely innervation targets for these axons,

\section{A. Control}

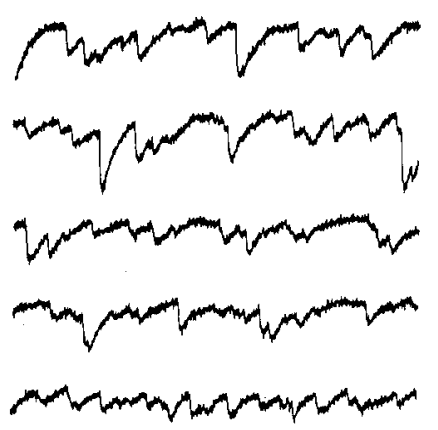

B. $100 \mu \mathrm{M}$ ACPD

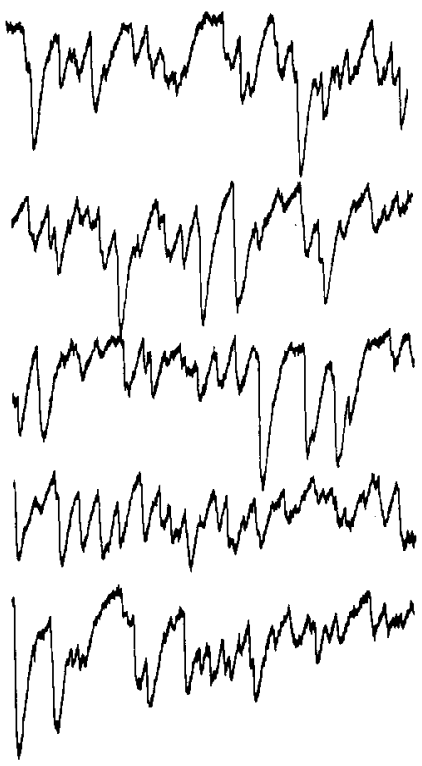

C. ACPD + Picrotoxin

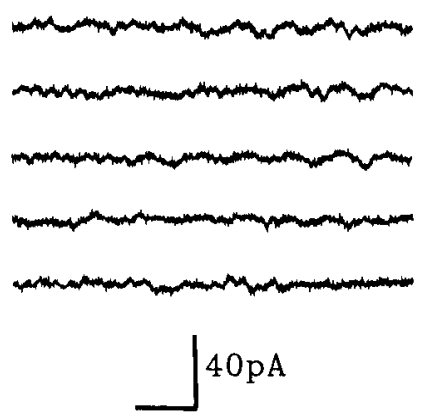

$100 \mathrm{msec}$
Figure 7. ACPD increases the incidence of spontaneous IPSCs recorded in a CA1 pyramidal cell. Five consecutive traces shown from the control pe$\operatorname{riod}(A)$, a period $5 \mathrm{~min}$ after bath application of $100 \mu \mathrm{M}$ ACPD $(B)$, and 5 min after bath application of $100 \mu \mathrm{M}$ picrotoxin $(C)$. The patch pipette contained $40 \mu \mathrm{M} \mathrm{CsCl}$ so that IPSCs recorded at $-70 \mathrm{mV}$ are inward currents. EPSCs were blocked using $20 \mu \mathrm{M}$ DNQX and $50 \mu \mathrm{M}$ D-AP5. 
therefore, are the distal dendrites of pyramidal neurons or possibly afferent nerve terminals in st. lacunosum, which include the perforant path from entorhinal cortex (Schwartzkroin et al., 1990).

\section{Discussion}

We have used ACPD as a probe to distinguish two functionally distinct interneuron groups within st. oriens. The two types of st. oriens interneuron are certain to play very different roles in the local hippocampal circuit, inhibiting distinct anatomical regions. The large oscillatory inward current we observe in one group of interneurons results from mGluRs on the interneurons themselves, and these neurons may be identical to those reported to express high levels of mRNA for mGluRl and to immunostain for mGluR $1 \alpha$ (Masu et al., 1991; Baude et al., 1993). Both classes of interneuron exhibit an enhanced EPSC in the presence of ACPD. Our experiments suggest that this is a consequence of mGluRs located presynaptically; the most likely site is on CA1 pyramidal cells or their terminals.

\section{Postsynaptic $m G l u R$ receptors mediate the large oscillatory response}

The major functional difference we observed between interneurons in st. oriens is the presence or absence of the large oscillatory inward current induced by ACPD. The inward current differs from those resulting from trans-ACPD treatment of cultured Purkinje cells (Staub et al., 1992) or of CA3 st. pyramidale interneurons (Miles and Poncer, 1993). The current and voltage changes described in these previous studies, although of similar magnitude, were associated with neither the large increase in Inembrane noise nor current oscillations we observed. In addition, we did not observe the prominent outward current following the inward current described by Staub et al. (1992). Interneurons of CA3 st. pyramidale exposed to high concentrations of trans-ACPD simply entered a depolarizing block of action potential firing without the depolarizing/repolarizing episodes we have observed (Miles and Poncer, 1993).

Metabotropic glutamate receptors are linked through GTPbinding proteins to a variety of intracellular second-messenger systems, and the dependence of the large inward current on intracellular GTP is consistent with activation of these receptors. Recent work by Baude et al. (1993) has demonstrated a high level of mGluR $1 \alpha$ in cells morphologically identical to the horizontally oriented st. oriens interneurons we have found to be potently responsive to ACPD. We have not attempted to identify which mGluR subtype is responsible for the oscillatory inward current; however, our results are consistent with activation of $\operatorname{mGluR} 1 \alpha$, and subsequent activation of phospholipase C. Blockade of the large inward current by intracellular BAPTA but not by extracellular $\mathrm{Co}^{2+}$ implicates the release of calcium from intracellular stores. Calcium oscillations resulting from $m$ GluR activation have also been demonstrated previously in cultured hippocampal neurons (Murphy and Miller, 1988). The oscillatory nature of the inward current we observed is reminiscent of membrane potential oscillations in other systems resulting from cyclical release of $\mathrm{Ca}^{2+}$ from, and its subsequent sequestration into, intracellular stores (for review, see Dupont et al., 1991; Henzi and MacDermott, 1992).

Another second messenger in addition to $\mathrm{Ca}^{2+}$ may be needed to trigger the large oscillatory inward current (e.g., diacylglycerol arising from phospholipase ( activation). Recently Fotuhi et al. (1993) have demonstrated that cells located in CA1 st. oriens express high levels of $\mathrm{mGluR} 1$ and protein kinase $\mathrm{C}$ (PKC), while lacking $\mathrm{IP}_{3}$ receptors. These data suggest the possibility that PKC mediates the majority of the effects of the metabotropic glutamate receptors on these cells. As PKC is a calciumactivated enzyme, our results with intracellular BAPTA are also consistent with this idea.

Although we have eliminated many possibilities, we have not yet identified the membrane component that carries the large inward current. We have ruled out the involvement of voltageactivated $\mathrm{Na}^{+}, \mathrm{K}^{+}$, and $\mathrm{Ca}^{2+}$ currents, as well as the involvement of ionotropic glutamate receptor activation. Part of the inward current could be carried by $\mathrm{Ca}^{2+}$-activated nonselective cation channels, as suggested by the increase in membrane conductance and by the outward current recorded at $+50 \mathrm{mV}(<20 \%$ of total current, assuming a linear $I-V$ relationship and $E_{\text {rcv }}=$ $0 \mathrm{mV}$ ) (Partridge and Swandulla, 1988). The remaining inward current and associated baseline noise may be due to a $\mathrm{Na}^{+} /$ $\mathrm{Ca}^{2+}$ exchange carrier, similar to that described for trans-ACPD activation of Purkinje cells (Staub et al., 1992). This is consistent with the slow time course of the response, and its apparent lack of a true reversal potential. $\mathrm{Ca}^{2+}$ release from cytoplasmic stores would be expected to activate the electrogenic $\mathrm{Na}^{+} / \mathrm{Ca}^{2+}$ exchange carrier as part of the regulatory mechanism to maintain constant $\left[\mathrm{Ca}^{2+}\right]_{i}$ levels. Elevated levels of $\left[\mathrm{Ca}^{2+}\right]_{i}$, at a negative membrane potential, will generate an inward current. As the membrane is depolarized the $\mathrm{Na}^{+}$gradient will be reduced, so over the range of $-70 \mathrm{mV}$ to $+50 \mathrm{mV}$ the current will be smaller, but it will not reverse polarity. Replacement of $\left[\mathrm{Na}^{+}\right]_{0}$ by $\mathrm{Li}^{+}$ prevents the inward current induced by ACPD in Purkinje neurons (Staub et al., 1992). A similar experiment was not possible in our system since the substitution of $\mathrm{Li}^{+}$for $\mathrm{Na}^{+}$resulted in a large increase in both synaptic activity and baseline noise, leading to instability of the interneuron membrane (C. J. McBain and J. A. Kauer, unpublished observations).

\section{Presynaptic mGluRs mediate enhancement of EPSCs}

The enhancement of the excitatory input to st. oriens interneurons results from activation of mGluRs located on presynaptic cells. Both CA3 and CA1 pyramidal cells depolarized in response to ACPD, as reported previously (Stratton et al., 1989; Desai and Conn, 1991; Hu and Storm, 1991). Afferents from either cell type could mediate the increased frequency of spontaneous EPSCs and the increased size of the evoked EPSC. Both classes of st. oriens interneuron showed an increase in EPSC amplitude, suggesting that these morphologically and functionally distinct interneuron groups are similarly innervated by pyramidal cells. Direct depolarization of the pyramidal neuron population will increase the intracellular calcium available for the synaptic release mechanism, leading to greater transmitter release. Additionally, trans-ACPD broadens the action potential (Hu and Storm, 1991) and reduces potassium currents in pyramidal neurons (Baskys et al., 1990; Charpak et al., 1990). A relatively small change in action potential duration can produce large changes in $\left[\mathrm{Ca}^{2+}\right]_{i}$ (Jackson et al., 1991), resulting in increased transmitter release.

The enhancement of the EPSC recorded from st. oriens interneurons described here is in marked contrast to the effects observed on other CAl interneurons. EPSCs recorded from interneurons of st. lacunosum and st. radiatum are markedly depressed by $1 S, 3 R$-ACPD (Desai et al., unpublished observations). EPSPs recorded in immature CAl pyramidal neurons are similarly depressed by trans-ACPD acting on presynaptic 
metabotropic receptors (Baskys and Malenka, 1991). We report that in st. oriens interneurons, ACPD significantly reduces the frequency of miniature EPSCs recorded in TTX, supporting the notion that at least some afferent terminals have mGlu autoreceptors that depress transmitter release. Based on our finding and the above-mentioned earlier studies, we speculate that it is the terminals of CA3 pyramidal cells that have these mGluR receptors, while CA $\perp$ pyramidal cell terminals do not have receptors that depress synaptic transmission. We therefore hypothesize that the enhancement of the cvoked EPSC we obscrve in st. oriens interneurons results from excitation of CAl pyramidal cells.

Potentiation of both amplitude and frequency of spontaneous excitatory input onto st. oriens interneurons will facilitate EPSC summation and increase the likelihood of action potential generation and the resulting inhibitory synaptic currents onto target cells postsynaptic to the st. oriens interneurons. Current-clamp recordings from CAl pyramidal cells have previously shown that the evoked IPSP is depressed by trans-ACPD (Desai and Conn, 1991; Pacelli and Kelso, 1991). Paradoxically, our finding that ACPD enhances excitatory transmission onto st. oriens interneurons suggests that these cells should cause an increase in inhibition. Two mechanisms may help explain this apparent discrepancy. The observations made by others involved evoked inhibitory responses, while we only monitored changes of spontaneous inhibitory input to pyramidal cells. It is possible that the observed evoked IPSP depression results from the stimulation of strongly depolarized interneurons, resulting in an apparent decrease in the evoked inhibition. If the interneurons contributing to the IPSP are stimulated during the large depolarizing oscillatory phase, many of these cells may well be refractory for action potential firing and the resulting evoked IPSP on pyramidal neurons reduced. Alternatively, it is possible that our st. oriens/alveus interneurons do not contribute to the evoked responses observed by others. In support of this hypothesis, we are unable to identify unequivocally the postsynaptic targets of these neurons, although the distal dendrites of CAl pyramidal neurons are a possibility. In addition, Lacaille (1987), using paired recordings, reported that only $7 \%$ of st. oriens/alveus interneurons were synaptically connected to $\mathrm{CA} 1$ pyramidal neurons, further suggesting that these interneurons do not make a major contribution to the evoked IPSP recorded at the cell body. Finally, the evoked IPSP undoubtedly arises from the stimulation of a heterogeneous population of interneurons. We have previously shown that one population of CAl interneurons located in st. radiatum do, in fact, show a depression of their evoked EPSC, a mechanism that likely contributes to the depression of the evoked IPSP seen by others.

Interestingly, Bortolotto and Collingridge (1993) have demonstrated that $1 S, 3 R$-ACPD caused a long-lasting potentiation of the EPSP at CA1/CA3 pyramidal cell synapses. While the EPSC potentiation we observed is qualitatively similar, it is reversible and does not result in a persistent potentiation (Bashir et al., 1993). The divergent effects in different hippocampal cell types undoubtedly arise from the differential expression and localization of the various members of the mGluR family throughout the hippocampal neuronal population.

We think it is unlikely that an increase in NMDA receptor activation (Kinney and Slater, 1992) accounts for the enhancement of the EPSC we observed since significant NMDA receptor activation should be prevented at a holding potential of -70 $\mathrm{mV}$ (Mayer et al., 1984; Nowak et al., 1984). The rise time and decay time constant of EPSCs are identical in the presence and absence of ACPD (see Table 1), suggesting that NMDA currents at distal dendritic sites are unlikely to contribute significantly to the enhanced EPSC. In addition, in two experiments where it was tested, EPSC enhancement was observed in the presence of an NMDA receptor antagonist (100 $\mu \mathrm{M}$ D-AP5).

\section{Possible functions of mGluR activation of st. oriens interneurons}

The magnitudes and temporal differences in receptor activation for the two classes of st. oriens interneurons will produce distinct effects on their respective postsynaptic targets. The small 2-3 $\mathrm{mV}$ depolarization of the vertically oriented interneurons will simply increase the frequency of ongoing inhibitory synaptic transmission, since most interneurons fired spontaneous action potentials under control conditions. These interneurons most probably release GABA, and their dense innervation of pyramidal cell bodies in a local region will strongly limit the firing of the innervated cells, through hyperpolarization and the shunting of current. This mechanism is no doubt responsible, in part, for the increased IPSCs we observed in CA1 pyramidal neurons. A similar increase in IPSP frequency has been demonstrated in pyramidal neurons of CA3 (Miles and Poncer, 1993). This effect, however, was attributed to increased action potential firing in interneurons resulting from the blockade of afterhyperpolarizations (AHPs). This is quite different from the depolarizations observed in our cells since $100 \mu \mathrm{M}$ ACPD was without effect on the AHPs of both types of interneuron (McBain and Kauer, unpublished observations).

The horizontally oriented interneurons responded to ACPD with strong depolarization and a dramatically increased frequency of firing. The targets of these neurons are not certain. We were unable to identify any changes in the GABAergic input to st. lacunosum interneurons, suggesting that these cells are not innervated by st. oriens interneurons. Two other likely synaptic targets include the distal apical dendrites of the CAl pyramidal neuronal population, and the presynaptic terminals of the perforant path. Activation of mGluRs on the horizontally oriented interneurons would be expected to produce very potent inhibition in st. lacunosum, strongly hyperpolarizing and shunting pyramidal cell dendritic currents mediated by GABA $\mathrm{A}_{\mathrm{A}}$ and GA$\mathrm{BA}_{\mathrm{B}}$ receptors, and perhaps reducing excitatory synaptic transmission at perforant path/CA1 pyramidal cell synapses. A large increase in action potential firing in the horizontally oriented interneurons may also result in release of somatostatin in st. lacunosum, since these cells (as well as some vertically oriented interneurons) are morphologically identical to somatostatincontaining cells (Kunkel and Schwartzkroin, 1988; Naus et al., 1988; Baude et al., 1993). The effects of this peptide in the region are not known, but somatostatin may modulate the activity of presynaptic terminals of perforant path axons (Schwartzkroin et al., 1990).

Further work is needed to ascertain what the duration and magnitude of the large inward current would be under physiological conditions of mGluR activation. However, we speculate that the inward current would have a slow onset and decline due to the second messenger cascade discussed above. The precise cellular location of mGluRs on the interneuron (somatic or dendritic) will also determine the effects of receptor activation on cell excitability.

It is not clear whether the slow voltage oscillations we observed occur under physiological conditions. The oscillations 
observed under our experimental conditions might, however, be expected to occur in pathological situations such as electrographic seizures, which are accompanied by a large increase in extracellular glutamate (for review, see McBain et al., 1993). The depolarization is reminiscent of the paroxysmal depolarizing shift usually associated with cortical pyramidal neurons displaying epileptiform activity (Finch and Jackson, 1990). The existence of a depolarizing/hyperpolarizing mechanism ensures that these st. oriens interneurons are phasically available to generate inhibitory synaptic currents even when faced with an initial depolarization that would otherwise inactivate the spike generating mechanism.

Although the great majority of st. oriens interneurons fall neatly into two classes based on morphology and response to ACPD, 4 of 15 vertically oriented cells did respond to ACPD with a large inward current. It is possible that an additional small class of cells exists in st. oriens with properties of both cell types.

\section{St. oriens interneurons may group target cells by inhibiting them synchronously}

The restricted termination patterns of st. oriens interneuron axons suggest that local regions of hippocampus are functionally linked together by single st. oriens interneurons. The vertically oriented cells densely innervate st. pyramidale. Assuming that these interneurons release GABA onto the pyramidal cell somata, a burst of interneuron firing is likely to inhibit firing simultaneously in a large cluster of nearby pyramidal cells. This functional clustering of pyramidal cells could be used to synchronize the output of the innervated pyramidal cells. The axons of horizontally oriented interneurons also terminate in a restricted region in st. lacunosum. This termination pattern is also likely to synchronize the electrical activity of local elements, although it is difficult to specify the mechanism until the postsynaptic target cells and neurotransmitters released by these interneurons are clearly defined.

In conclusion, by correlating morphological and physiological information, we have found two separate and functionally distinct groups of interneurons in st. oriens of hippocampus. These groups will influence the local circuit in distinct ways. Although both types of interneuron are depolarized by mGluR activation, the far more potent activation of horizontally oriented interneurons suggests that glutamatergic afferents onto this class of cells are likely to provide strong, long-lasting excitation. Both classes of st. oriens interneuron receive an excitatory input that is strongly potentiated by mGluR activation, due to depolarization of pyramidal neurons that synapse onto both types of st. oriens interneuron.

The present results suggest that large clusters of pyramidal cells can potentially be synchronized by individual interneurons of st. oriens. Presumably the entire CAl region is divided into clusters of pyramidal cells whose electrical activity can be controlled by individual interneurons. The view of interneurons as "gatekeepers" of pyramidal cell clusters emphasizes the importance of understanding how interneurons are modulated by neurotransmitters.

\section{References}

Alger BE, Nicoll RA (1982) Feed-forward dendritic inhibition in rat hippocampal pyramidal cells studied in vitro. J Physiol (Lond) 328: $105-123$.

Bashir ZI, Bortolotto ZA, Davies CH, Berretta N, Irving AJ, Seal AJ,
Henley JM, Jane DE, Watkins JC, Collingridge GL (1993) Induction of LTP in the hippocampus needs synaptic activation of glutamate metabotropic receptors. Nature 363:347-350.

Baskys A, Malenka RC (1991) Agonists at metabotropic glutamate receptors presynaptically inhibit EPSCs in neonatal rat hippocampus. J Physiol (Lond) 444:687-701.

Baskys A, Bernstein N, Barolet A, Carlen P (1990) NMDA and quisqualate reduce a $\mathrm{Ca}$-dependent $\mathrm{K}$ ' current by a protein kinase-mediated mechanism. Neurosci Lett 112:76-81.

Baude A, Nusser Z, Roberts JDB, Mulvihill E, McIlhinney RAJ, Somogyi P (1993) The metabotropic glutamate receptor (mGluR $1 \alpha$ ) is concentrated at perisynaptic membrane of neuronal subpopulations as detected by immunogold reaction. Neuron 11:771-787.

Bortolotto ZA, Collingridge GL (1993) Characterisation of LTP induced by the activation of glutamate metabotropic receptors in area CAl of the hippocampus. Neuropharmacology 32:1-9.

Charpak S, Gähwiler BH, Do KQ, Knöpfel T (1990) Potassium conductances in hippocampal neurons blocked by excitatory amino-acid transmitters. Nature 347:765-767.

Desai M, Conn J (1991) Excitatory effects of ACPD receptor activation in the hippocampus are mediated by direct effects on pyramidal cells and blockade of synaptic inhibition. J Neurophysiol 661:40-52.

Dupont G, Berridge MJ, Goldbeter A (1991) Signal-induced $\mathrm{Ca}^{2+}$ oscillations: properties of a model based on $\mathrm{Ca}^{2+}$-induced $\mathrm{Ca}^{2+}$ release. Cell Calcium 12:73-85.

Fdwards FA, Konnerth A, Sakmann B, Takahashi T (1989) A thin slice preparation for patch clamp recordings from neurones of the mammalian central nervous system. Pfluegers Arch 414:600-612.

Finch DM, Jackson MB (1990) Presynaptic enhancement of synaptic transmission in hippocampal cell cultures by phorbol esters. Brain Res 518:269-273.

Fotuhi M, Sharp AH, Glatl CE, Hwang PM, von Krosigk M, Snyder SH, Dawson TM (1993) Differential localization of phosphoinositide-linked metabotropic glutamate receptor (mGluRl) and the inositol 1,4,5-trisphosphate receptor in rat brain. J Neurosci 13:20012012.

Hamill OP, Marty A, Neher E, Sakmann B, Sigworth FJ (1981) Improved patch-clamp techniques for high-resolution current recording from cells and cell-free membrane patches. Pfluegers Arch 391:85100

Henzi V, MacDermott AB (1992) Characteristics and function of $\mathrm{Ca}^{2+}$ and inositol 1,4,5-trisphosphate-releasable stores of $\mathrm{Ca}^{2+}$ in neurons. Neuroscience 16:251-273.

Houamed KM, Kuijper JL, Gilbert TL, Haldeman BA, O'Hara PJ, Mulvihill ER, Almers W, Hagen FS (1991) Cloning, expression, and gente structure of a $G$ protein-coupled glutamate receptor from rat brain. Science 252:1318-1321.

Hu G-Y, Storm JF (1991) Excitatory amino acids acting on metabotropic glutamate receptors broaden the action potential in hippocampal neurons. Brain Res 568:339-344.

Jackson MB, Konnerth A, Augustine GJ (1991) Action potential broadening and frequency-dependent facilitation of calcium signals in pituitary nerve terminals. Proc Natl Acad Sci USA 88:380-384.

Kinney G, Slater T (1992) Potentiation of mossy fiber-evoked EPSPs in turtle cerebellar Purkinje cells by the metabotropic glutamate receptor agonist 1S,3R-ACPD. J Neurophysiol 67:1006-1008.

Kunkel DD, Schwartzkroin PA (1988) Ultrastructural characterization and GAD co-localization of somatostatin-like immunoreactive neurons in CAl of rabbit hippocampus. Synapse 2:371-381.

Lacaille J-C (1991) Postsynaptic potentials mediated by excitatory and inhibitory amino acids in interneurons of stratum pyramidale of the CAl region of rat hippocampal slices in vitro. J Neurophysiol 66: 1441-1454.

Lacaille J-C, Schwartzkroin PA (1988) Stratum lacunosum-moleculare interneurons of hippocampal CAl region. I. Intracellular response characteristics, synaptic responses, and morphology. J Neurosci $8: 1400-1410$.

Lacaille J-C, Williams S (1990) Membrane properties of interneurons in stratum oriens-alveus of the CAl region of rat hippocampus in vitro. Neuroscience 36:349-359.

Lacaille J-C, Mueller AL, Kunkel DD, Schwartzkroin PA (1987) Local circuit interactions between oriens/alveus interneurons and CAl pyramidal cells in hippocampal slices: electrophysiology and morphology. J Neurosci 7:1979-1993.

Livsey CT, Vicini S (1992) Slower spontaneous excitatory postsynaptic currents in spiny versus aspiny hilar neurons. Neuron 8:745-755. 
Lorente de No R (1934) Studies on the structure of the cerebral cortex. II. Continuation of the study of the ammonic system. J Psychol Neurol 46:113-177.

Masu M, Tanabe Y, Tsuchida K, Shigemoto R, Nakanishi S (1991) Sequence and expression of a metabotropic glutamate receptor. $\mathrm{Na}$ ture 349:760-765.

Mayer ML, Westbrook GL, Guthrie PB (1984) Voltage-dependent block by $\mathrm{Mg}^{2+}$ of NMDA responses in spinal cord neurones. Nature 309:261-263.

McBain CJ, Dingledine R (1993) Heterogeneity of synaptic glutamate receptors on $\mathrm{CA} 3$ st. radiatum interneurones of rat hippocampus. J Physiol (Lond) 462:373-392.

McBain CJ, Traynelis SF, Dingledine R (1993) High potassium-induced synchronous bursts and electrographic seizures. In: Epilepsy: models, mechanisms and concepts (Schwartzkroin PA, ed). Cambridge: Cambridge UP.

Miles R (1991) Tetanic stimuli induce a short-term enhancement of recurrent inhibition in the CA3 region of guinea-pig hippocampus in vitro. J Physiol (Lond) 443:669-682.

Miles R, Poncer J-C (1993) Metabotropic glutamate receptors mediate a post-tetanic excitation of guinea-pig hippocampal inhibitory neurones. J Physiol (Lond) 463:461-473.

Miles R, Wong RKS (1984) Unitary inhibitory synaptic potentials in the guinea-pig hippocampus in vitro. J Physiol (Lond) 356:97-113.

Miles R, Wong RKS (1987) Inhibitory control of local excitatory circuits in the guinea-pig hippocampus. J Physiol (Lond) 388:611629.

Miller RJ (1991) Metabotropic excitatory amino acid receptors reveal their true colors. Trends Pharmacol Sci 12:365-357.

Murphy SN, Miller RJ (1988) A glutamate receptor regulates $\mathrm{Ca}^{2+}$ mobilization in hippocampal neurons. Proc Natl Acad Sci USA 85 $8737-8741$.

Naus CC, Morrison JH, Bloom FE (1988) Development of somato- statin-containing neurons and fibers in the rat hippocampus. Brain Res 468:113-121.

Nicoletti F, Wroblewski JT, Fadda E, Costa E (1988) Pertussis toxin inhibits signal transduction at a specific metabotropic glutamate receptor in primary cultures of cerebellar granule cells. Neuropharmacology 27:551-556.

Nowak L, Bregestovski P, Ascher P (1984) Magnesium gates glutamate-activated channels in mouse central neurones. Nature 307:462465.

Pacelli G, Kelso S (1991) Trans-ACPD reduces multiple components of synaptic transmission in the rat hippocampus. Neurosci Lett 132: 267-269.

Partridge LD, Swandulla D (1988) Calcium activated non-specific cation channels. Trends Neurosci 11:69-72.

Pitkanen A, Amaral DG (1993) Distribution of parvalbumin-immunoreactive cells and fibers in the monkey temporal lobe: the hippocampal formation. J Comp Neurol 331:37-74

Ramon y Cajal S (1968) The structure of Ammon's horn. Springfield, IL: Thomas.

Schoepp D, Bockaert J, Sladeczek F (1990) Pharmacological and functional characteristics of excitatory amino acid receptors. Trends Pharmacol Sci 11:508-515.

Schwartzkroin PA, Scharfman HF, Sloviter RS (1990) Similarities in circuitry between Ammon's horn and dentate gyrus: local interactions and parallel processing. Prog Brain Res 83:269-286.

Staub C, Vranesic I, Knopfel T (1992) Responses to metabotropic glutamate receptor activation in cerebellar Purkinje cells: induction of inward current. Eur J Neurosci 4:832-839.

Stratton KD, Worley PF, Baraban JM (1989) Excitation of hippocampal neurons by stimulation of glutamate Qp receptors. Eur J Pharmacol 173:235-237.

Traub RD, Miles R (1991) Neuronal networks of the hippocampus. Cambridge: Cambridge UP. 